\title{
NOTES
}

\section{Synthesis of Soluble Polyimides Based on Alicyclic Dianhydride in Ionic Liquids}

\author{
Yusuke TsudA, ${ }^{1, \dagger}$ Tetsuya YoshidA, ${ }^{2}$ and Takahiko KAKOI ${ }^{1}$ \\ ${ }^{1}$ Department of Biochemistry \& Applied Chemistry, Kurume National College of Technology, \\ 1-1-1 Komorino, Kurume 830-8555, Japan \\ ${ }^{2}$ Advanced Engineering School, Kurume National College of Technology, \\ 1-1-1 Komorino, Kurume 830-8555, Japan
}

(Received June 13, 2005; Accepted August 23, 2005; Published January 15, 2006)

\begin{abstract}
KEY WORDS Polyimide / Polymerization / 5-(2,5-Dioxotetrahydrofuryl)-3-methyl-3-cyclohexene1,2-Dicarboxylic Anhydride / Ionic Liquid /

[DOI 10.1295/polymj.38.88]
\end{abstract}

Ionic liquids are low-melting-point salts that have characteristic properties such as absence of flammability, lack of measurable vapor pressure, good ability to dissolve organic compounds, and catalytic effects. Recently ionic liquids have become utilized as a reaction medium for many organic reactions including polymer synthesis. ${ }^{1}$

Polyimides exhibit excellent thermal and mechanical properties, and have extensive engineering and microelectronics applications. ${ }^{2}$ Since conventional aromatic polyimides are insoluble, extensive research has been recently carried out to improve the solubility of polyimides. ${ }^{3-11}$ The authors also have systematically investigated the synthesis of soluble polyimides based on alicyclic tetracarboxylic anhydrides, ${ }^{12-14}$ aromatic diamines having long chain alkyl groups, ${ }^{15,16}$ and dendric moiety on their side chain. ${ }^{17}$ In these studies, conventional volatile organic compounds (VOC) such as $\mathrm{N}$-methyl-2-pyrrolidone (NMP) were used for polymerization solvents. On the other hand, there were only a few papers that ionic liquids were used as solvents for polyimide synthesis. ${ }^{18,19}$ This paper reports the application of ionic liquid as solvents for the synthesis of alicyclic polyimides that have the same structure reported previously in our lab, ${ }^{14}$ and the merit of ionic liquids are clarified.

\section{EXPERIMENTAL}

\section{Materials}

1-Butyl-3-methylimidazolium hexafluorophospate ([bmim] $\mathrm{PF}_{6}$ ), 1-hexyl-3-methylimidazolium hexafluorophospate ([hmim] $\mathrm{PF}_{6}$ ), 1-octhyl-3-methyl imidazolium hexafluorophospate ([omim] $\left.\mathrm{PF}_{6}\right)$, and 1-butyl-3methylimidazolium bromide $([\mathrm{bmim}] \mathrm{Br})$ were kindly supplied by The Nippon Synthetic Chemical Industry Co., Ltd. 5-(2,5-Dioxotetrahydrofuryl)-3-methyl-3-cyclohexane-1,2-dicarboxylic anhydride (cyclohexeneDA) and 4,4'-diaminodiphenyl ether (DDE) were purchased from Tokyo Chemical Industry Co., Ltd. (TCI) and purified by recrystallization; cyclohexene-DA, mp. $175.1^{\circ} \mathrm{C}$, recrystallized from acetic anhydride; DDE, mp. $193.6^{\circ} \mathrm{C}$, recrystallized from ethanol. Other conventional reagents were purchased from TCI or Wako Pure Chemical Industries, Ltd. and used as received.

\section{Measurements}

The inherent viscosities of all polymers were measured using Cannon Fenske viscometers at a concentration of $0.5 \mathrm{~g} / \mathrm{dL}$ in NMP at $30^{\circ} \mathrm{C} .{ }^{1} \mathrm{H}$ NMR spectra were measured on a JEOL JNM-AL400 FT NMR in dimethyl sulfoxide- $d_{6}$ with tetramethylsilane (TMS) as an internal reference. IR spectra were measured on a JASCO IR Report-100 spectrophotometer.

\section{Preparation of Polyimides}

As a typical example, to a $20 \mathrm{~mL}$ flask was added $4.75 \mathrm{~g}$ of $[\mathrm{bmim}] \mathrm{PF}_{6}$ and the system was purged by argon, and then heated to $130^{\circ} \mathrm{C}$. To above solution was added $0.108 \mathrm{~g}(0.538 \mathrm{mmol})$ of DDE by portion under argon flow while the system was heated to $180^{\circ} \mathrm{C}$. Finally, to this mixture was added $0.142 \mathrm{~g}$ $(0.538 \mathrm{mmol})$ of cyclohexene-DA by portion, and the system was stirred at $180^{\circ} \mathrm{C}$ under argon flow for $1 \mathrm{~h}$. Powdered polyimides were obtained by precipitation into $100 \mathrm{~mL}$ of methanol, filtered, and washed with a large amount of methanol, and then purified three times by reprecipitation technique using NMP as a good solvent and methanol as a poor solvent, and finally dried at $100^{\circ} \mathrm{C}$ for $1 \mathrm{~d}$.

${ }^{\dagger}$ To whom correspondence should be addressed (Tel: +81-942-35-9408, FAX: +81-942-35-9329, E-mail: tsuda@kurume-nct.ac.jp). 
<smiles>CC1=CC(C2CC(=O)OC2=O)CC2C(=O)OC(=O)C12</smiles>

Cyclohexene-DA<smiles>Nc1ccc(Oc2ccc(N)cc2)cc1</smiles>

DDE

Ionic Liquid

$180^{\circ} \mathrm{C}, 0.5-4 \mathrm{~h}$<smiles>CC1=CC(C2CC(=O)N(C(C)(C)C)C2=O)CC2C(=O)N(c3ccc(Oc4ccc(C(C)(C)C)cc4)cc3)C(=O)C12</smiles>

Ionic Liquid;<smiles>[2H]n1cc[n+](C)c1</smiles>

bmim: $R=$ buthyl hmim: $R=$ hexyl omim: $\mathrm{R}=$ octhyl

Scheme 1. Synthesis of polyimides based on cyclohexene-DA and DDE using ionic liquids as solvents.

Table I. Polymerization of cyclohexene-DA and DDE in an ionic liquid

\begin{tabular}{|c|c|c|c|c|c|}
\hline \multirow[b]{2}{*}{ Entry } & \multirow[b]{2}{*}{ Ionic liquid ${ }^{\mathrm{a}}$} & \multicolumn{2}{|c|}{ Reaction condition ${ }^{\mathrm{b}}$} & \multicolumn{2}{|c|}{ Polyimide } \\
\hline & & $\begin{array}{l}\text { Time } \\
\text { (h) }\end{array}$ & $\begin{array}{c}\text { Consentration } \\
(\text { wt } \%)\end{array}$ & $\begin{array}{l}\text { Solubility } \\
\text { (in IL) }\end{array}$ & $\begin{array}{c}\eta_{\text {inh }}{ }^{\mathrm{c}} \\
\left(\mathrm{dL} \mathrm{g}^{-1}\right)\end{array}$ \\
\hline 1 & {$[\mathrm{bmim}] \mathrm{PF}_{6}$} & 1.5 & 5 & soluble & 0.31 \\
\hline 2 & {$[\mathrm{hmim}] \mathrm{PF}_{6}$} & 1.5 & 5 & soluble & 0.30 \\
\hline 3 & [omim] $\mathrm{PF}_{6}$ & 1.5 & 5 & partly soluble & 0.14 \\
\hline 4 & {$[\mathrm{bmim}] \mathrm{PF}_{6}$} & 1.0 & 5 & soluble & 0.25 \\
\hline 5 & {$[\mathrm{bmim}] \mathrm{PF}_{6}$} & 3.0 & 5 & soluble & 0.36 \\
\hline 6 & {$[\mathrm{bmim}] \mathrm{PF}_{6}$} & 4.0 & 5 & insoluble & - \\
\hline 7 & {$[\mathrm{bmim}] \mathrm{PF}_{6}$} & 0.5 & 10 & soluble & 0.24 \\
\hline 8 & {$[\mathrm{bmim}] \mathrm{PF}_{6}$} & 1.0 & 10 & soluble & 0.42 \\
\hline 9 & {$[\mathrm{bmim}] \mathrm{PF}_{6}$} & 1.5 & 10 & soluble & 0.53 \\
\hline 10 & {$[\mathrm{bmim}] \mathrm{PF}_{6}$} & 2.0 & 10 & insoluble & - \\
\hline 11 & [bmim] $\mathrm{Br}$ & 3.0 & 10.0 & soluble & 0.20 \\
\hline 12 & $m$-cresol ${ }^{\mathrm{d}}$ & 8.0 & 20.0 & soluble & 0.33 \\
\hline
\end{tabular}

abmim; 1-buthyl-3-methylimidazolium, hmim; 1-hexyl-3-methylimidazolium, omim; 1-octhyl-3-methylimidazolium. ${ }^{\mathrm{b}}$ Equimolar amount of cyclohexene-DA and DDE was used. Polymerization temperature; $180^{\circ} \mathrm{C}$. ${ }^{\mathrm{c}}$ Measured at $0.5 \mathrm{~g} \mathrm{dL}^{-1}$ in NMP at $30^{\circ} \mathrm{C}$. ${ }^{\mathrm{d}}$ Polymerization condition; $80^{\circ} \mathrm{C}, 2 \mathrm{~h}-200^{\circ} \mathrm{C}, 6 \mathrm{~h}$.

\section{RESULTS AND DISCUSSION}

The experimental results of synthesis of polyimides using cyclohexene-DA and DDE as monomers, and $[$ bmim $] \mathrm{PF}_{6},[\mathrm{hmim}] \mathrm{PF}_{6}$ and $[\mathrm{omim}] \mathrm{PF}_{6}$ as solvents were summarized in Scheme 1 and Table I. Although various compounds are known as ionic liquids, $N, N^{\prime}-$ dialkylimidazolium hexafluorophosphates were chosen because these are commonly available room-temperature ionic liquids and easy to handle. According to our pre-experiments, it was found that dissolution temperature and the addition order of monomers are important. Specifically, it was found to be necessary to dissolve DDE in ionic liquids over $c a .130^{\circ} \mathrm{C}$, and then add cyclohexene-DA by portion while the temperature was elevated to $180^{\circ} \mathrm{C}$. If these monomers were added simultaneously at lower temperature, the homogeneous solutions were not obtained and precipitation took place.

Firstly, the difference of three kinds of ionic liquids ([bmim] $\mathrm{PF}_{6},[\mathrm{hmim}] \mathrm{PF}_{6}$ and $[\mathrm{omim}] \mathrm{PF}_{6}$ ) was examined under the same polymerization conditions (time; $1.5 \mathrm{~h}$, monomer concentration; $5 \mathrm{wt} \%$ ), and it was 
observed that homogeneous solutions were obtained in case of $[\mathrm{bmim}] \mathrm{PF}_{6}$ and $[\mathrm{hmim}] \mathrm{PF}_{6}$, while the precipitation took place in case of $[\mathrm{omim}] \mathrm{PF}_{6}$ (Table I, Entry 1-3). It can be assumed that longer alkyl chains decrease the polarities of ionic liquids and hence reduce the solubility of polyimides. Obtained polyimides were carefully purified by reprecipitation and well characterized by ${ }^{1} \mathrm{H}$ NMR and IR in agreement with our previous results. ${ }^{14}$

Secondly, the effect of polymerization time was examined (Table I, Entry 4-6, Entry 7-10). The inherent viscosities $\left(\eta_{\text {inh }}\right)$, which are connected to the molecular weights of polymers, were measured in NMP. It was found that longer polymerization time gave the high molecular weight polyimides, however excess polymerization times caused precipitation of polyimides (Table I, Entry 6, 10). Thirdly, the higher molecular weight polyimides were obtained in shorter time in case the monomer concentration was increased from 5 to $10 \mathrm{wt} \%$ (Table I, Entry 7-9). However, in the case of higher monomer concentration over 10 wt $\%$, the proceeding of polymerization became difficult because of precipitation of polyimides.

The following two polymerization experiments were carried out as comparative methods (Table I, Entry 11-12). $m$-Cresol that is the common solvent for one-step polymerization of polyimides was used under the same condition previously reported. ${ }^{17,18}$ Consequently, the molecular weight (inherent viscosity) of polyimide obtaind in $m$-cresol was lower than the one obtained in $[\mathrm{bmim}] \mathrm{PF}_{6}$. It can be assumed that the catalytic effects are existed in polyimide synthesis using ionic liquids as the reaction medium. Since the data of ref 18 demonstrated that $N, N^{\prime}$-dialkylimidazolium bromide gave the higher molecular weight polyimides in comparison with the corresponding hexafluorophosphates, [bmim] $\mathrm{Br}$ was examined instead of [bmim] $\mathrm{PF}_{6}$. Consequently, [bmim] $\mathrm{Br}$ gave a lower molecular weight (inherent viscosity) polyimide probably due to the fact that $[\mathrm{bmim}] \mathrm{PF}_{6}$ have the stronger catalytic effect than $[\mathrm{bmim}] \mathrm{Br}$ in the case of our study. Since the difference between our study and ref 18 is that the type of monomers is different, the suitable ionic liquids for the polyimide synthesis are probably depend on the type of monomers.

In conclusion, the best polymerization condition was Entry 9 in Table I ([bmim] $\mathrm{PF}_{6}, 1.5 \mathrm{~h}, 10 \mathrm{wt} \%$, $180^{\circ} \mathrm{C}$ ) and it gave the highest molecular weight polyimides $\left(\eta_{\text {inh }} ; 0.53\right)$. According to our previous study using NMP as a polymerization solvent, the same cyclohexene-DA/DDE polyimides $\left(\eta_{\mathrm{inh}} ; 0.53\right)$ was obtained from two-step reaction including the poly(amic acids) synthesis (r.t., $12 \mathrm{~h}$, in NMP) and chemical imidization reaction $\left(120^{\circ} \mathrm{C}, 4 \mathrm{~h}\right.$, in NMP with acetic anhydride and pyridine as catalysts). ${ }^{14}$ As compared with two methods, the following merits were found in case of using ionic liquids, namely, ionic liquids can give the same molecular weight polyimides by shorter reaction time without additional catalysts. Since alyciclic dianhydrides are low reactive monomers, ${ }^{12-14}$ it is recognized that the use of ionic liquids are the valuable method for the formation of relevant polyimides.

Acknowledgment. The authors thank The Nippon Synthetic Chemical Industry Co., Ltd. for providing ionic liquids.

\section{REFERENCES}

1. M. Freemantle, $C \& E N /$ November 8,44 (2004).

2. a) K. L. Mittal, Ed., "Polyimides: Synthesis, Characterization, and Application," Vol. 1-2, Plenum Press, New York, N.Y., 1984.

b) M. K. Ghosh and K. L. Mittal, Ed., "Polyimides," Marcel Dekker, New York, N.Y., 1996.

3. T.-S. Leu and C.-S. Wand, J. Appl. Polym. Sci., 87, 945 (2003).

4. D.-J. Liaw and W.-T. Tseng, Macromol. Symp., 199, 351 (2003).

5. H. Fan, Y. Gu, and M. Xie, J. Polym. Sci., Part A: Polym. Chem., 41, 554 (2003).

6. C.-P. Yang, R.-S. Chen, and K.-H. Chen, J. Polym. Sci., Part A: Polym. Chem., 41, 922 (2003).

7. C.-P. Yang, R.-S. Chen, and H.-C. Chiang, Polym. J., 35, 662 (2003).

8. S.-H. Hsiao, C.-L. Chung, and M.-L. Lee, J. Polym. Sci., Part A: Polym. Chem., 42, 1008 (2004).

9. D.-J. Liaw and F.-C. Chang, J. Polym. Sci., Part A: Polym. Chem., 42, 5766 (2004).

10. S.-H. Hisao and K.-H. Lin, J. Polym. Sci., Part A: Polym. Chem., 43, 331 (2005).

11. D.-J. Liaw, F.-C. Chang, M. Leung, M.-Y. Chou, and K. Muellen, Macromolecule, 38, 4024 (2005).

12. Y. Tsuda, Y. Tanaka, K. Kamata, N. Hiyoshi, S. Mataka, Y. Matsuki, M. Nishikawa, S. Kawamura, and N. Bessho, Polym. J., 29, 574 (1997).

13. Y. Tsuda, K. Etou, N. Hiyoshi, M. Nishikawa, Y. Matsuki, and N. Bessho, Polym. J., 30, 222 (1998).

14. Y. Tsuda, R. Kuwahara, K. Fukuda, K. Ueno, and J.-M. Oh, Polym. J., 37, 126 (2005).

15. Y. Tsuda, T. Kawauchi, N. Hiyoshi, and S. Mataka, Polym. J., 32, 594 (2000).

16. Y. Tsuda, K. Kanegae, and S. Yasukouchi, Polym. J., 32, 941 (2000).

17. Y. Tsuda, R. Kuwahara, and J.-M. Oh, Transactions of the Materials Research Society of Japan, 29, 267 (2004).

18. Y. S. Vygodskii, E. I. Lozinskaya, and A. S. Shaplov, Macromol. Rapid Commun., 23, 676 (2002).

19. E. I. Lozinskaya, A. S. Shaplov, and Y. S. Vygodskii, Eur. Poym. J., 40, 2065 (2004). 